NBER WORKING PAPER SERIES

\title{
COMPREHENSIVE VERSUS SELECTIVE SCHOOLING \\ IN ENGLAND IN WALES: \\ WHAT DO WE KNOW?
}

\author{
Jörn-Steffen Pischke \\ Alan Manning \\ Working Paper 12176 \\ http://www.nber.org/papers/w12176
NATIONAL BUREAU OF ECONOMIC RESEARCH
1050 Massachusetts Avenue
Cambridge, MA 02138
April 2006

We thank Ghazala Azmat and Michele Pellizzari for excellent research assistance. We thank seminar participants at the NBER Education Program Meetings and particularly Esther Duflo for helpful comments on a previous version of this paper. Pischke thanks the NBER for their hospitality during a visit when much of the work for this project was performed. The views expressed herein are those of the author(s) and do not necessarily reflect the views of the National Bureau of Economic Research.

(C2006 by Jörn-Steffen Pischke and Alan Manning. All rights reserved. Short sections of text, not to exceed two paragraphs, may be quoted without explicit permission provided that full credit, including $\odot$ notice, is given to the source. 
Comprehensive versus Selective Schooling in England in Wales: What Do We Know?

Jörn-Steffen Pischke and Alan Manning

NBER Working Paper No. 12176

April 2006

JEL No. I21, I28

\begin{abstract}
British secondary schools moved from a system of extensive and early selection and tracking in secondary schools to one with comprehensive schools during the 1960s and 70s. Before the reform, students would take an exam at age eleven, which determined whether they would attend an academically oriented grammar school or a lower level secondary school. The reform proceeded at an uneven pace in different areas, so that both secondary school systems coexist during the 1960s and 70s. The British transition therefore provides an excellent laboratory for the study of the impact of a comprehensive versus a selective school system on student achievement. Previous studies analyzing this transition have typically used a value-added methodology: they compare outcomes for students passing through either type of school controlling for achievement levels at the time of entering secondary education. While this seems like a reasonable research design, we demonstrate that it is unlikely to successfully eliminate selection effects in who attends what type of school. Very similar results are obtained by looking at the effect of secondary school environment on achievement at age 11 and controlling for age 7 achievement. Since children only enter secondary school at age 11, these effects are likely due to selection bias. Careful choice of treatment and control areas, and using political control of the county as an instrument for early implementation of the comprehensive regime do not solve this problem.
\end{abstract}

Jörn-Steffen Pischke

Centre for Economic Performance

London School of Economics

Houghton Street

London WC2A 2AE

UK

and NBER

s.pischke@1se.ac.uk
Alan Manning

Centre for Economic Performance

London School of Economics

Houghton Street

London WC2A 2AE

UK

a.manning@1se.ac.uk 


\section{Introduction}

National school systems differ widely in the amount of ability tracking of students they provide in secondary school. Some systems (e.g. the US) are based on comprehensive schools, where students of all abilities attend the same school, although there is typically some tracking within schools. Other systems (e.g. Germany) channel students at an early age into different types of schools based on academic ability. British schools moved from a system of extensive tracking to one with comprehensive schools in the 1960s and 70s. The British experience is interesting, because it involved a major and well defined change in terms of the ability grouping of secondary school students. Hence, it offers potentially very promising research designs in order to assess the impact of the secondary school regime on student achievement. It is unsurprising that numerous studies in the education and economics of education literatures analyze the British experience.

In the traditional British school system, students were tracked into either an academically selective grammar school at age 11, or they would attend a secondary modern school, which was academically less demanding. Starting in the 1950s, there was dissatisfaction with selection at the local level, and some local authorities began to experiment with comprehensive schools. In 1965, the central government asked the Local Education Authorities (LEAs) to draw up plans to switch to a comprehensive system. The implementation proceeded slowly, with faster growing, more Labour leaning LEAs moving to comprehensive schools more quickly, while those without expanding numbers of students, and more Conservative leaning Authorities implemented the change more slowly. In fact, there are still a number of LEAs to date which provide grammar schools as an option.

Much of the research on comprehensive education in Britain uses the National Child Development Study (NCDS), a panel which tracks members of the 1958 birth cohort. The sample members entered secondary school in 1969, at a time when some LEAs in Britain had started to provide comprehensive schools already, while others continued to offer the traditional selective schools. Hence, the comparisons using the NCDS are essentially cross-sectional. While Kerckhoff et al. (1996) claim that comprehensive areas differ little from selective areas, we find that comprehensive areas are systematically poorer, and have students with lower previous achievement. A raw comparison of students attending comprehensive and selective 
schools is therefore not possible. Most previous studies rely on some form of a value added specification, where student performance at age 16 is a function of student performance at age 11, the secondary school environment, and possibly other control variables.

This seems an entirely reasonably research design, particularly since the NCDS offers a large set of controls on student ability and family background. We demonstrate in this paper that this methodology is nevertheless unlikely to be completely successful in removing the selection bias between comprehensive and selective school students. The NCDS provides test scores at ages 7 , 11, and 16. It is therefore possible to run an analogous specification for student performance at age 11 on student performance at age 7, and the secondary school environment. Since students at age 11 have not started attending secondary school yet, the secondary school environment should have no influence on age 11 outcomes if the specification successfully removes the selection bias. This exercise is therefore a falsification test for the value added specification.

OLS value added specifications tend to lead to a small negative average effect of comprehensive schooling compared to selective schooling in our sample. We demonstrate that effects of a similar size or larger are obtained when using age 11 test scores as outcomes. This suggests that the methodology is unable to remove the selection bias between students attending different schools. A more interesting finding of the previous literature (particularly Kerkhoff et al., 1996) may be that comprehensive schools tend to be equalizing, in that they lower the performance of the most able students, and raise the performance of the least able. We show that this result is also likely due to selection bias.

We also demonstrate that various approaches to improve on the methodology used previously are not more successful. Most studies on this question compare students attending comprehensive and selective schools. Since many LEAs were in the middle of comprehensive reorganization in the 1970s, these schools often coexisted within the same LEA. A better use of the policy variation, possibly removing some of the selection, is the comparison of LEAs which are either purely comprehensive or purely selective in 1969, when the NCDS cohort enters secondary school. We show that this does not help in removing the selection bias. Another approach is the use of instrumental variables (IV) for comprehensive reorganization (see, for example, GalindaRueda and Vignoles, 2004). Political control of the county is a good predictor of early 
reorganization, and conditional on county socio demographic characteristics is a plausible instrument. We show that the IV strategy similarly fails.

At a theoretical level, there are good arguments for selection as well as for comprehensive education. The main argument for selection or tracking is presumably that it is much easier to teach lower variance classes. Since teachers can focus on the ability level of particular groups of students, students of all ability levels might benefit from selection. One argument against selection is that there might be positive peer effects from the most able students. By tracking these students into separate classrooms, the most able students may benefit from being with each other. However, the lower ability ranges loose from not having this peer group around. We know very little about the different impact of peer group effects on different types of students empirically, so it is difficult to judge a priori whether this leads to lower or higher average performance in a selective system.

Another argument, particularly against early selection as in post-war Britain, is that eventual ability levels are difficult to predict at an age as early as 10 or 11 . Moreover, secondary selection is based on a single exam, clearly a noisy mechanism. This may result in some kids ending up in the wrong track. This suggests that particularly middle ability kids may loose in the British style selective system. Since there are arguments going either way, the issue eventually is an empirical one.

The findings in the empirical literature about selection differ widely. Many researchers looking at the British secondary reorganization conclude that the evidence does not support claims to the superiority of either system (see, for example, Crook, Power, and Whitty, 1999). On the other hand, there are also studies which find more pronounced effects going one way or the other. Jesson (2000) uses data from the 1990s on those LEAs which still remain selective. Also using a value added approach, he argues that comprehensive LEAs systematically outperform selective LEAs in Britain. Based on the findings from the NCDS, these results are equally suspect. We conclude that little can be learned from the existing literature on the British reorganization on the performance of comprehensive versus selective schools.

Two recent papers by Hansushek and Wößmann (2006) and Waldinger (2006) apply an approach roughly similar to ours to educational inequality across countries. Both papers investigate 
whether inequality in educational outcomes is related to the amount of secondary school tracking and selection across countries. These papers apply a differences-in-differences approach comparing outcomes between secondary and primary schooling. Hanushek and Wößmann find evidence that tracking raises educational inequality, while Waldinger does not. However, Waldinger shows that the Hanushek and Wößmann results are not very robust to alternative sample and variable specifications.

The remainder of this paper is organized as follows. The next section briefly describes the institutional background of British secondary education, and the history of comprehensive reorganization. Section 3 discusses the empirical framework, and the approaches used in some of the existing literature. The following section describes the data and key variables. Results are discussed in section 5 , and the final section concludes.

\section{Secondary Education in Britain ${ }^{1}$}

After World War II, secondary education was provided mainly in grammar and secondary modern schools. The $11+$ exam, taken at the age of 10 or 11, determined whether a student was allowed to attend the selective and academically oriented grammar school. About 25 percent of students would attend grammars, with the remainder attending less challenging secondary modern schools. While this was the consensus model, education policy making in Britain was always rather decentralized, with the local educational authorities (LEAs) being the main administrative units, which retained a lot of decision making power about the exact make-up of the local school system. The 1944 Education Act only prescribed separate secondary schools and a transfer at age 11 leaving open the possibility for LEAs to experiment with other schemes, including comprehensive schools. Early drives for the establishment of comprehensives at the local level were typically, although not exclusively, in Labour dominated urban areas, like London, Bristol, and Coventry.

The existing consensus about secondary schooling at the national level also began to crack in the 1950s. There was growing unease about the selection process using the 11+ examination, which

\footnotetext{
${ }^{1}$ This section draws heavily on the descriptions in Kerkhoff et al. (1996) and Griffith (1971).
} 
determined the admission to grammar schools. Moreover, it became obvious that there were other alternatives to a selective system than large comprehensive schools serving all children age 11 to 18 at once. The Leicestershire LEA, for example, began to experiment with abandoning the $11+$ and creating a comprehensive school up to age 14 .

By the early 1960s, many, if not most, LEAs were working on reorganization plans, which were trying to end the traditional selective system, or were challenging it in one way or another. While Labour led LEAs played a leading role in this development, the trend cut across party lines, with some Conservative authorities being among the most fervent advocates to ending selection. As a response, the 1964 Education Act passed by the Conservative government abandoned the principle of school transfer at age 11 .

Only in 1963 had the Labour Party fully embraced the comprehensive principle at the national level and called for the end of selection at their party conference. When Labour came to power in 1964, its goal was to accelerate the existing trend for comprehensive reorganization, which was well underway at the local level. However, there was a great diversity of views on how this reorganization should be achieved. Rather than compelling LEAs on a particular system of comprehensive schooling, the government issued Circular 10/65 in July 1965, requesting local authorities to submit detailed plans on how to establish comprehensives. The circular itself suggested no fewer than six different models of comprehensive reorganization. The middle school model, pioneered in Leicestershire, often turned out to be popular with Conservatives, because it allowed them to retain the grammar schools as the upper schools (an example is the Leeds LEA). Nevertheless, in practice, most comprehensive schools eventually became 11 - 16 or $11-18$ schools.

By the mid-1960s, secondary education in England and Wales was rather diverse. In some LEAs, comprehensive reorganization had been well under way for years. The majority were drawing up plans to respond to the central government's request in some way or another. A small number of LEAs resisted the call by the central government completely. This diversity was not limited to the LEAs but often extended to divisions and districts within the LEAs. Overall, the period from 1965 to 1974 was one where new comprehensive schools were established in most parts of the country, and the fraction of students served by these schools increased dramatically. In 1965, there were still only 262 comprehensive schools in England and 
Wales. By 1974 this number had grown to 2,677, and these were attended by 62 percent of secondary students in LEA maintained schools (see Figure 1).

One of the key issues of contention during this period was less the establishment of comprehensive schools, as the closing of existing grammar schools, some of which had a long tradition. As a result, new comprehensive schools often coexisted with the traditional grammar schools in many places, hence perpetuating selection despite reorganization. There was also great variety in the form the new comprehensive schools took. Some were purpose built, others were amalgamated out of existing schools, often on different physical sites. Some served pupils until they reached the university entrance exams at age 18 (A-levels), while others ended at 16 and students who wanted to stay in school longer were served by separate so called sixth form colleges.

The pace of reorganization was very different in different places as well. When the Conservatives won the national elections in 1970, Education Secretary Margaret Thatcher effectively rescinded circular 10/65. But this change in national policy was unable to stem the existing tide, and, in fact, more comprehensives were opened under Mrs. Thatcher's helm at the Education Department than under any of her predecessors or successors. Nevertheless, while the change in the government did not reverse the longer-term trend, the comprehensive movement never regained the same thrust it had during the 1960s. Comprehensive reorganization, while concentrated in the 1960s and 70s, does continue into the 1990s (see Figure 1). A few LEAs still maintain grammar schools, and the political discussion about the merits of selection continue in Britain until this day.

This investigation, like many previous ones, focuses on England and Wales, which went through the protracted transformation process just described. Scotland transformed to a comprehensive system more quickly, and without much local discretion. Nevertheless, Scotland is not particularly useful as a comparison group because it has a very different educational system from England and Wales with its own school leaving exams and university system (undergraduate degrees taking 4 years compared to 3 in England). Northern Ireland kept the selective system during this period but it is not included in the NCDS, and also differs sufficiently from the rest of the UK to make a comparison difficult. 


\section{Methodological Considerations and Comparison with the Previous Literature}

The goal of the investigation is to determine how a student or set of students who were educated in a comprehensive school would have fared, had they been part of the selective system instead. Beyond the impact of the secondary system on the average outcomes on students, we might be interested in the distributional aspects of the policy change: for example, do high ability or low ability students benefit more from one system or the other. The main challenge in the evaluation of these questions is that participation in comprehensive schooling may be correlated with the ability or family background of the student.

Suppose that outcomes for a student at age 16 are given by the following linear relationship

$y_{16 i}=\alpha_{16}+\beta_{16} C_{i}+\gamma_{16} A_{i}+\delta_{16} F_{i}+\lambda_{16} S_{i}+\varepsilon_{16 i}$

where $y_{16 i}$ is the test score at age $16, C_{i}$ is an indicator for a student attending a comprehensive school, and $A_{i}, F_{i}$ and $S_{i}$, are the student's ability, family background, and primary school inputs, respectively. The coefficient $\beta_{16}$ measures the impact of comprehensive schooling on student achievement and is the parameter of interest. $\gamma_{16}, \delta_{16}$, and $\lambda_{16}$ are the loadings on ability, family background, and primary school inputs for age 16 achievement. These effects may be different from the loadings for outcomes at other ages. $\varepsilon_{16}$ is a random term, due to the fact that test scores measure actual student achievement only with error, to account for differences in secondary school inputs other than comprehensive schooling etc. A similar relationship to (1) holds for student achievement at age 11:

$y_{11 i}=\alpha_{11}+\gamma_{11} A_{i}+\delta_{11} F_{i}+\lambda_{11} S_{i}+\varepsilon_{11 i}$

and $C_{i}$ does not enter in this case.

The key challenge in estimating the relationship in (1) is that complete information particularly on ability but possibly also on the relevant family background and school input variables is not available. In order to overcome this data deficiency, researchers have turned to "value added models.” Instead of trying to estimate (1) directly, these models estimate 
$y_{16 i}=\alpha+\beta C_{i}+\rho y_{11 i}+\eta_{16 i}$

In order to compare (3) to the earlier equations (1) and (2), multiply (2) by $\rho$ and subtract it from both sides of (1). This yields:

$y_{16 i}=\alpha_{o}+\beta_{16} C_{i}+\rho y_{11 i}+\left(\gamma_{16}-\rho \gamma_{11}\right) A_{i}+\left(\delta_{16}-\rho \delta_{11}\right) F_{i}+\left(\lambda_{16}-\rho \lambda_{11}\right) S_{i}+\varepsilon_{16 i}-\rho \varepsilon_{11 i}$

It is obvious from (4) that the value added model implies the restriction $\gamma_{16}=\rho \gamma_{11}$ and analogous ones for the other parameters (see Todd and Wolpin, 2003, for a more detailed discussion of the restrictions inherent in the value added model). These are stringent restrictions: they say, for example, that the effect of ability has a reduced impact on student achievement at age 16 compared to age 11 (assuming that $\rho<1$ ), and this reduction is the same as the reduction in the impact of primary school inputs.

One way to address this problem is to let the lagged test score proxy ability (which is typically most difficult to observe), and to include additional controls for family background and primary school inputs in (3), so that the augmented value added model now takes the form:

$y_{16 i}=\alpha^{\prime}+\beta^{\prime} C_{i}+\rho y_{11 i}+\delta F_{i}+\lambda S_{i}+\eta_{16 i}^{\prime}$

This is a model which is frequently estimated in the literature, e.g. it is the specification adopted by Kerkhoff et al. (1996).

If the restrictions leading to the value added specification (3) are true, then the coefficients $\delta$ and $\lambda$ in (5) should be zero. Estimating (5) and testing this restriction is therefore effectively a test of the narrower value added model (suggested, for example, by Todd and Wolpin, 2003). Maybe more importantly, even if $\delta$ and $\lambda$ are non-zero in (5), if the estimates of $\beta$ from (3) and $\beta$ ' from (5) are very similar, this is an indicator that the remaining family background factors and primary school inputs are largely orthogonal to the comprehensive school assignment, conditional on the lagged test score. This would generally raise the researcher's confidence that other potentially omitted factors are also orthogonal to the comprehensive school treatment. We will therefore look at this implication in our data below. 
Looking at (4) makes clear that measurement error in age 11 test scores will be part of the error term of that equation. If $C_{i}$ is correlated with true age 11 achievement, then measurement in the test scores will invariably bias the estimate of $\beta$, the coefficient of interest. We will be able to explore this issue because multiple test scores are available on the NCDS. Hence it is possible to instrument one test score with an alternative score.

Return to student achievement at age 11 as described in equation (2). If we want to estimate this equation, we face the same problem that particularly ability is not available. However, the NCDS also contains age 7 test scores so that we can estimate:

$y_{11 i}=\alpha^{\prime \prime}+\rho^{\prime \prime} y_{7 i}+\eta_{11 i}^{\prime \prime}$

or possibly (6) augmented by family background factors and pre-primary inputs. Notice from the discussion above that the value added model essentially implies a stationary student achievement process. If equation (3) is valid for age 16 achievement, then equation (6) ought to be valid for age 11 achievement. Moreover, the coefficients $\rho$ and $\rho$ " ought to be the same (except for the fact that there is only a four year gap between 7 and 11, while there is a five year gap between 11 and 16).

Most important for our investigation, including the indicator $C_{i}$ in (6) serves as a specification test. To the degree that the secondary school environment does not affect outcomes at age 11, it should have a zero coefficient if (6) is correctly specified. If comprehensive schooling matters for age 11 test scores, then this implies that equation (6) is misspecified. Given the close analogies between equations (6) and (3), this most likely implies that (3) or (5) are misspecified as well.

The studies by Kerkhoff et al. (1996) and Galinda-Rueda and Vignoles (2005) both focus on comparing students attending comprehensive schools with students attending selective schools. However, as we argued above, comprehensive and selective schools coexisted in the majority of LEAs at the time the NCDS cohort entered secondary schools. The bulk of the identification will therefore come from these mixed LEAs. But if grammar schools coexist alongside comprehensive schools in the LEA it is unclear whether the comprehensive schools will really have an intake which is representative of all students or whether the grammar schools will keep 
cream skimming the best students. The comprehensive schools would effectively just be relabeled secondary modern schools in this case. This approach also makes no direct use of the policy variation introduced by the British transition to comprehensive education. ${ }^{2}$

As an alternative, we also compare students in LEAs which are purely selective with those in LEAs which are purely comprehensive in 1969. This approach is not without problems either, because LEAs which switched to the comprehensive system early enough for the 1969 entering cohort tend to be systematically poorer and have lower ability students. Nevertheless, there are two advantages to this approach. The first is that only these pure LEAs truly compare a comprehensive and a selective regime. Comprehensive schools in mixed LEAs may have a very different composition because of the cream skimming effect. The second advantage is that the control strategy in equations (3) or (5) is more believable when only the between LEA variation is being used. Whether a student attended, say, a comprehensive or a grammar school within an LEA is a question of individual school choice. The controls therefore need to reflect all the factors relevant to that individual choice. While this is a tall order, across LEAs we only need to control for the fact that the average characteristics of students in comprehensive and selective LEAs differ. Measurement error and omitted variables are therefore likely to be of much less consequence.

A different approach is to estimate versions of equations (3) or (5) by instrumental variables. Galinda-Rueda and Vignoles (2005) present estimates where they use political control in the county as an instrument for comprehensive school attendance. The discussion above suggested that this might be a valid instrument, conditional on county socio-demographic characteristics. The validity of the IV approach can similarly be checked by estimating the age 11 model. Since the instrument is an LEA level variable, we implement this approach only in the LEA level analysis.

\footnotetext{
${ }^{2}$ Kerkhoff et al. (1996) acknowledge this problem, and also compare only LEAs which are either purely selective or purely comprehensive. However, they downplay this approach because it results in relatively small sample sizes.
} 


\section{Data and Variables}

Our main data source is the National Child Development Study (NCDS). The survey includes everyone born between March 3 and 9, 1958. After a parental survey at birth, there were followups at ages 7, 11, 16, 23, 33, and 41. The original survey included 17,414 births. However, the study has had significant attrition, and by the time of the fifth wave at age 33, information is only available for 11,407 sample members. Extensive information on the life course of each individual is available, including interviews with the sample member, parents, teachers, health professionals, and results on aptitude and medical tests, as well as on official school leaving exams (O-levels and A-levels). Our sample includes all individuals in England and Wales, on whom there is information from the schools in the age 7,11 , and 16 surveys.

We make no attempt to replicate the exact results in any specific previous study. Sample and variable definitions are therefore idiosyncratic to this analysis. A variety of achievement tests were given to the NCDS sample members at ages 7,11, and 16. Each test is scored on its own scale. In order to make results easier to read, we have converted all test scores to a $0-100$ scale. The key outcome measure we analyze is the math test score at age 16 . The same reading test was given to the sample members at ages 11 and 16, and the test was not really appropriate at age 16. As a consequence, we concentrate on the math test results at 16. A variety of other outcomes would be available (like O-level and A-level participation and results, post-secondary schooling, etc.). However, test score outcomes have featured prominently in the previous literature. They also most easily allow the comparison with age 11 outcomes.

In order to classify LEAs as either comprehensive or selective, we relied on data on school attendance by LEA from Education Statistics for the years 1967, 1971, and 1974, and on descriptions of secondary reorganization plans in Comprehensive Schools Committee (1967) and Benn (1971). The NCDS distinguishes 164 LEAs in 1969. According to our classification there are 26 comprehensive and 29 selective LEAs with observations in the sample, while 109 LEAs are not used. A list is given in appendix table 3.

We supplemented the NCDS data with some area characteristics from the 1971 Census, which we merged with the 1969 residential LEA of the sample member. In addition, we collected data for the political composition of the county or county borough, which we use as instrumental 
variables. Local political control in Britain is organized in a number of counties. Some cities are administered independently of the counties (these are called county boroughs). The LEAs outside Greater London in 1969 coincided either with a county or county borough. We collected information on the outcomes of local elections in 1961 from the newspaper The Times and supplemented it with information from the Municipal Yearbook (1962). The Times typically also reported which party held control of the county council, which is the variable we use. Where this information is missing, and one party held the majority of the seats, we assigned control to that party. There are a few counties and county boroughs, which were established between 1961 and 1969. In these cases, we used political control in the main predecessor area in 1961.

\section{Empirical Results}

Table 1 shows regressions of the math test score at age 16 on a dummy variable whether the student attends a comprehensive school. Different specifications add different sets of control variables, which are described in Appendix table 1. Column (1) shows the raw difference between comprehensive school students and those attending selective schools, either grammars or secondary moderns. Comprehensive students score 7.7 points lower on average. This is about a third of the student level standard deviation of the math score, which is 22.4 , so that the raw difference is not insubstantial.

Of course, the raw difference probably reflects mostly the fact that comprehensive schools in the sample had a different intake than selective schools. Hence, column (2) presents a value added specification like equation (3) by adding the math test score at age 11, when students entered secondary school. The comprehensive coefficient now changes to -2.2 , only about a third the original difference. Nevertheless, this specification still indicates that comprehensive school students score worse than students in selective schools.

The remaining columns in the table probe whether this estimate might reflect the causal effect of comprehensive education using the standard technique of adding additional covariates. In column (3), we add four other age 11 test scores (a reading, verbal, non-verbal, and a design copy score). Adding these additional scores changes the result relatively little to about -2.1. 
Column (4) introduces demographic and family background variables, making this an augmented value added specification as in equation (5). The set of background variables is roughly similar to the ones used in Kerkhoff et al. (1996) (we use dummies for gender, more than two siblings, twins, no mother figure, no father figure, and four dummies for father's occupation). The estimate in column (4) changes relatively little compared to column (3). Finally, using almost 50 covariates about the family, primary school experience, and county characteristics in the last column yields a coefficient of $-1.5 .^{3}$ While this is closer to zero, it is still not very different from the estimate in column (2).

The test of the narrow value added specification suggested by Todd and Wolpin (2003) amounts to an F-test on the background variables in columns (4) and (5). The F-statistics are 27.9 and 11.9 respectively. Both are highly significant with p-values well below the 0.1 percent level. This means that the narrow value added specification is clearly rejected. On the other hand, the comprehensive school coefficient changes little as these covariates are added, suggesting that the background variables are more or less uncorrelated with the student attending a comprehensive school, conditional on the lagged test scores. Hence, it seems unlikely that other variables could be found which would change the estimate if added to the last specification. This would suggest that a coefficient in the order -2.0 or -1.5 actually reflects the causal effect of the comprehensive experience. An effect of this size, about 0.07 to 0.09 standard deviations of the math test score, is not huge but could well be of a plausible magnitude for a policy like comprehensive schooling.

Table 2 probes this conclusion by repeating the same exercise, but using the math test score at 11 as the dependent variable, and test scores at age 7 as the controls. The raw difference between selective and comprehensive school students in age 11 math scores in column (1) is 8.4, about the same magnitude as for the age 16 scores. Adding the age 7 math score lowers the difference only to 6.0. This may be due to the fact that the age 7 math score is not as good a predictor of age 11 performance, as the age 11 score is of age 16 performance. It is indeed the case that the raw correlation of age 16 and age 11 scores is much higher than that of age 11 and age 7 scores, 0.77 compared to 0.56 . This may not be surprising, since children are just learning basic arithmetic at age 7 , so the age 7 score is a more noisy measure of actual ability to do math at 11 .

\footnotetext{
${ }^{3}$ This results in a smaller sample because of missing values in some of the covariates. The change in the comprehensive coefficient from column (4) to (5) is entirely due to the additional covariates, not the change in the sample.
} 
Hence, it is not surprising that adding additional test scores for reading and drawing in column (3) makes more of a difference. The coefficient is -4.9 now. Similarly, the comprehensiveselective difference falls to 4.0 when the Kerkhoff et al. (1996) type background variables are added, and to 3.3 when a large set of about 40 background controls are added. The covariates are also highly significant again. These results probably all reflect that age 11 performance is more difficult to predict than performance at age 16. If we were to look at results like those in table 2, and wanted to draw a causal inference, we would be much more cautious because the results are more sensitive to the set of included controls.

But more importantly, the results in table 2 suggest that the value added specification, controlling for lagged test scores and background characteristics, is not a panacea in this context. If the strategy worked well in purging the regressions of any selection, we would expect the comprehensive school coefficient to be zero, at least in column (5). However, this coefficient is actually twice as large in absolute value as the corresponding coefficient in table 1 . If this result is likely to reflect selection bias, then we should be equally worried about the results in table 1.

There are various possibilities why we might expect a negative effect in table 2. One is that attending a comprehensive school in the future actually affected students during their primary school experience. Primary schools in selective areas would spend much time preparing children for the 11+ examination. Hence, it might not be surprising that students who eventually went to selective schools did much better on an age 11 exam than those going on to comprehensive schools. While there is certainly some truth to this explanation, we doubt that it can provide much comfort. It is unlikely that the primary school experience has twice as large an impact on student achievement than actually attending a comprehensive school, although it is of course possible.

Secondly, many of the comprehensive school students in this sample actually attended mixed LEAs. In many of those LEAs it might not have been clear during the primary years whether the child would eventually attend a selective or comprehensive school. Hence, comprehensive school students might have obtained the same exam preparation during their primary years. In order to examine this issue, we start from the specification in column (4) and limit the sample to LEAs that were neither clearly comprehensive nor clearly selective. Depending on how stringent this selection is done, we obtain coefficients between -4.4 and -3.8 , very similar to the coefficient 
in column (4). This may still not be the best comparison, because rural counties might have been mixed, but this reflects mostly differences between districts rather than mixing in the local areas. Hence, a better test is to limit the sample also to urban areas, where comprehensive and selective schools most likely coexisted in mixed areas. The range of coefficients is now -4.4 to -1.6 , with the latter number referring to the most stringent sample selection. Unfortunately, the sample sizes for this exercise are also small, and the standard errors also reach a size of 1.5. But even the most conservative estimate of -1.6 is still of the same magnitude as those in table $1 .^{4}$ So there is little reason to believe that the table 1 estimates do not simply reflect selection bias.

A further possibility for the larger differences found for comprehensive students in table 2 is the larger degree of measurement error in age 7 test scores. Since the lagged math test score seems to be the most important control variable, and adding other test scores has only a minor impact, we return to the specification with only the lagged math test score (but we now add the small set of background covariates). On the other hand, contemporaneous test scores are rather highly correlated (for example, the age 11 math test score has a raw correlation of 0.74 with the age 11 reading test score). Hence, we instrument the math test score either with the reading test score, or with all the other available test scores.

Results from this exercise are shown in table 3. Columns (1) and (4) show the OLS estimates. Columns (2) and (5) show the IV estimates, instrumenting the lagged math test score by the lagged reading test score. The coefficient on the lagged test score increases in each case but by a much larger amount in case of the regressions for the age 11 scores. In fact, the IV coefficient on the lagged test score is above 1 in column (5). At the same time, the coefficient on comprehensive schools drops in absolute value by about a third. This indicates that measurement error in the lagged scores might indeed be a problem, and this accounts for some of the estimated negative effects of the comprehensive experience. But again, this does not eliminate the negative estimates for the age 11 scores. Similar results are obtained in columns (3) and (6) using all the other lagged scores as instruments.

These results indicate that measurement error in lagged test scores is indeed important, and that it likely leads to bias in the coefficients of interest. Nevertheless, measurement error also is not the

\footnotetext{
${ }^{4}$ These results are robust to the type of adjustment we make for measurement error in table 3 below.
} 
explanation to the puzzle, since we still find strongly negative effects for age 11 scores. This means that selection remains a plausible and maybe even likely explanation for these findings, and hence sheds doubt on the age 16 results as well.

So far, we have only investigated the average effects of the comprehensive school experience. Much interest in the literature (e.g. Kerkhoff et al., 1996 and Galindo-Rueda and Vignoles, 2004) has focused on the distributional effects, however. Table 4 turns our attention to this issue. Like in Kerkhoff et al. (1996), we introduce an interaction between attending a comprehensive school and lagged ability. We summarize ability in this case by the average of the math, reading, verbal, and non-verbal test scores at age 11, and by the average of the math, reading, and drawing score at age 7 . The ability measures are also on a scale of $0-100$.

Like the previous authors, we find a strong interaction effect in column (1) for the age 16 results. While the main effect of attending a comprehensive school is positive, the interaction is negative. A hypothetical student at the $10^{\text {th }}$ percentile of ability (with a score of 24.6) would score about 1 point higher in math at age 16 after attending comprehensive school. Contrast this with a student at the $90^{\text {th }}$ ability percentile (scoring 75.8 ), who would score about 4 points lower after attending a comprehensive school. This result suggested to the previous authors that comprehensive schools are good for weaker students while selective schools are good for the better students. This is plausible, since the best students would be attending grammar schools in the selective system.

This conclusion is again tempered by the results in column (2), where we repeat the exercise with age 11 math scores. The basic result is the same, but the point estimates suggest an even steeper ability gradient. Hence, the ability interaction may also simply be due to selection effects. It suggests that comprehensives may have a more compressed intake in terms of abilities than selective schools. This could be because different types of schools attract different types of students, or because the areas switching to comprehensive schools earlier were more homogeneous.

Of course, using covariates to fully control for the selection in what type of secondary school a student attends is a tall order. So it may not be so surprising that this exercise fails. A more promising approach is to only use the variation at the LEA level by comparing LEAs which were 
solidly comprehensive or solidly selective for the NCDS students. This exploits the policy variation of the British experience more directly. Furthermore, controlling for differences in student characteristics at the LEA level should be much easier than at the student level. Hence, we repeat the same type of results for our subsample of LEAs, which we classified into one of these two categories.

Table 5 displays the results. The raw difference between students in comprehensive and selective LEAs is 5.8 points. This is smaller than the raw difference between all comprehensive and selective students. Nevertheless, it is large compared to the variation in test scores between LEAs, which is 9.1 using all LEAs. Adding control variables in column (2) again lowers the coefficient to about -1.5 , very similar to the finding in table 1 based on comprehensive school attendance. Furthermore, the interactions with lagged ability in column (3) also suggest similar distribution effects as in table 4, but these effects are now somewhat smaller in magnitude. Not surprisingly, the results are also less precise in this much smaller sample. Are the LEA level results likely more reliable? The results for the math score at age 11 suggest the opposite. These results are also very close to those in tables 2 and 4 . Hence, this strategy is not really any more convincing than the previous one either.

Finally, we follow the suggestion in Galindo-Rueda and Vignoles (2005) and use political composition of the county as an instrument for comprehensive status. Our instrument, conservative control of the county or borough in 1961, predicts comprehensive status very well. The t-statistic on the instrument in the first stage corresponding to column (1) in table 6 is 32.4. The IV estimate of the comprehensive effect is -2.6, slightly more negative than the OLS estimate in column (2) of table 5. We also repeat the specifications interacting ability with comprehensive status in column (2). In this case, we use the interaction of ability and conservative control as an instrument for the interaction term. Again, the results are roughly similar to the OLS results. Moreover, columns (3) and (4) show that we also obtain comparable results for the age 11 test scores yet again. The instrumental variables strategy also does not seem to be able to remove the selection bias successfully. 


\section{Conclusion}

We have argued in this paper that the experience in England and Wales provides potentially a useful experiment to study the impact of comprehensive versus selective schooling. Much of the research on this issue has adopted popular value added specifications for test score outcomes of affected and unaffected students. We have argued that a useful specification test for these types of models is to apply them to students during their primary school years by using age 11 test scores at the dependent variable, and controlling for age 7 test scores. As long as students do not fare differently in primary school, depending on whether they end up in a comprehensive or a selective school in the secondary system, these regressions should show a zero comprehensive effect if all selection is successfully controlled.

Our results indicate the opposite. Throughout the analysis, we have found rather similar patterns of results for the age 16 test scores and for the age 11 test scores. We conclude from this that it is prudent to be cautious about interpreting the age 16 results causally. As long as the age 11 results reflect selection bias, this may also be the case for the age 16 results.

Of course, it is possible to argue that our age 11 results are biased, while the age 16 specifications have removed all selection effects successfully. There are various arguments to make this case, like the fact that age 7 controls are poorer predictors of age 11 outcomes, the fact that primary school teaching may differ depending on whether the students are going to take the 11+ exam, etc. We have tried to show that none of these are likely to fully explain the age 11 results.

Nevertheless we agree that it is a possibility that the age 16 results are right and the age 11 results are wrong. However, identification always requires a leap of faith. We are typically willing to make this leap of faith when a research design seem particularly plausible (as in an experiment) or when we have prior knowledge or additional evidence that a particular identification strategy is likely to remove the selection bias successfully. In this case, we have presented evidence to the contrary: that there is a good case to be made that selection bias exists in the estimates comparing students in comprehensive and selective schools. Our case does not have to be ironclad to make us worried about the interpretations in the previous literature. 
Our worry also extends to studies which do not use the NCDS. Similar value added specifications have been applied to other data in order to answer this question (for example Jesson, 2000 using more recent data). While we have not explicitly demonstrated potential problems with these estimates, we would remain cautious in drawing strong conclusions from a research design that essentially mirrors that adopted by the studies analyzing the NCDS data. We conclude that we probably do not know very much about the effect of comprehensive schooling in Britain, or elsewhere for that matter. 


\section{References}

Benn, Caroline (1971) 1971 Survey of Comprehensive Reorganization Plans and Lists of Comprehensive Schools in England, Wales, and Scotland. Comprehensive Schools Committee.

Comprehensive Schools Committee (1967) Comprehensive Education. Secondary Reorganization in England and Wales. Survey No. 1 1966/7.

Crook, D.R., S. Power, and G. Whitty (1999) The Grammar School Question, London: Institute for Education.

Galindo-Rueda, Fernando and Anna Vignoles (2005) "The heterogeneous effect of selection in secondary schools: Understanding the changing role of ability,” CEE Discussion Paper No. 52.

Griffith, A. (1971) Secondary School Reorganization in England and Wales, London: Routledge \& Kegan Paul.

Hanushek, Eric and Ludger Wößmann (2006) "Does Educational Tracking Affect Performance and Inequality? Differences-in-Differences Evidence across Countries,” Economic Journal 116, C63-C76.

Jesson, David (2000) “The Comparative Evaluation of GCSE Value-Added Performance by Type of School and LEA," University of York Discussion Papers in Economics No. 2000/52.

Kerckhoff, Alan C., Ken Fogelman, David Crook, and David Reeder (1996) Going Comprehensive in England and Wales. A Study of Uneven Change, London: The Woburn Press.

Municipal Yearbook (1962, 1968) London: Municipal Journal Ltd.

Todd, Petra and Kenneth Wolpin (2003) "On the Specification and Estimation of the Production Function for Coginitive Achievement” Economic Journal 113, F3-F33.

Waldinger, Fabian (2006) "Does Tracking Affect the Importance of Family Background on Students' Test Scores?” mimeographed, London School of Economics 
Figure 1

Shares of Publically Supported Pupils by School Type

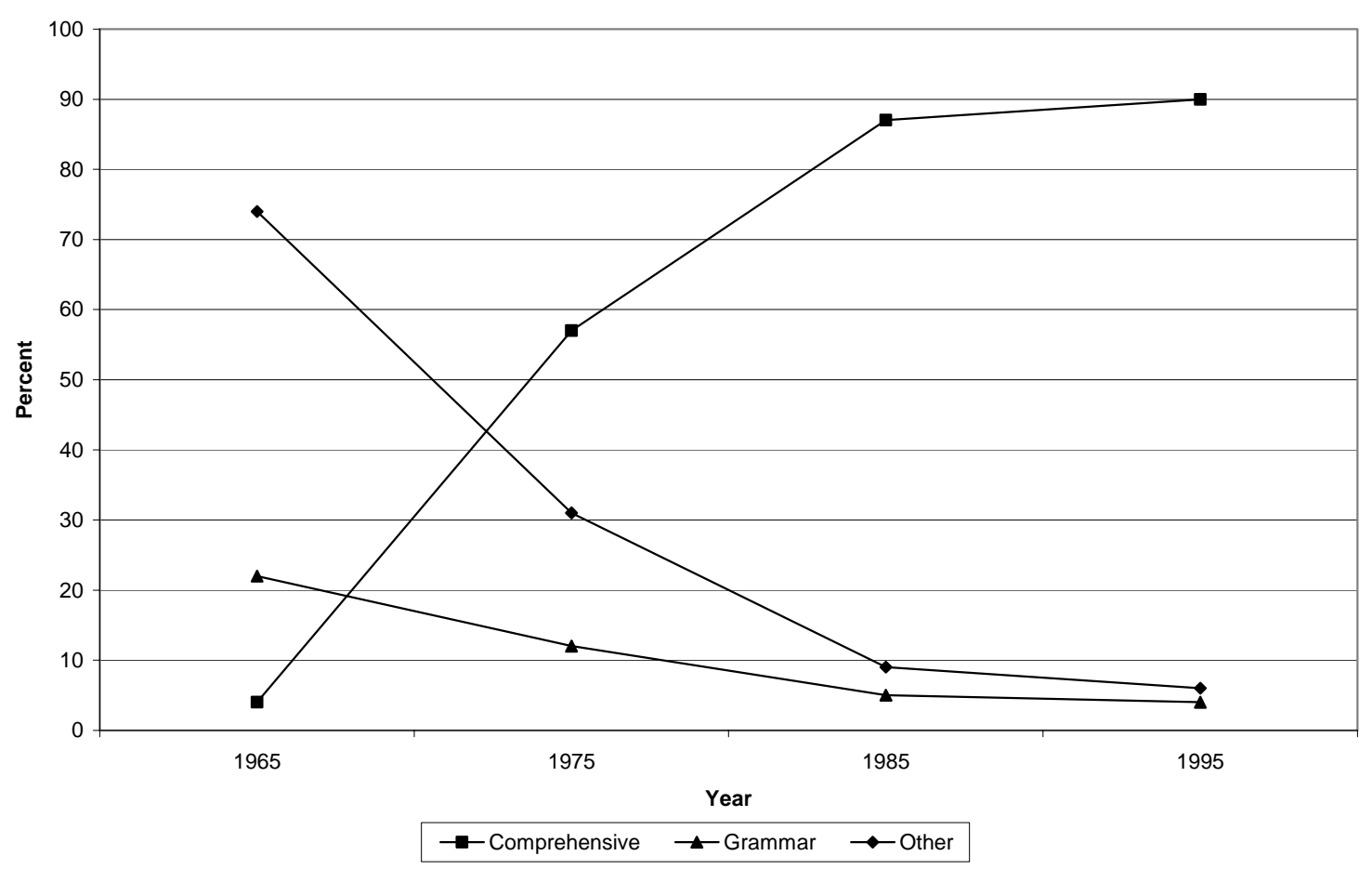


Table 1

Math Test Scores at 16

OLS Regressions

\begin{tabular}{|c|c|c|c|c|c|}
\hline Regressor & (1) & $(2)$ & (3) & (4) & (5) \\
\hline Attends Comprehensive School & $\begin{array}{c}-7.74 \\
(0.54)\end{array}$ & $\begin{array}{c}-2.18 \\
(0.35)\end{array}$ & $\begin{array}{l}-2.07 \\
(0.34)\end{array}$ & $\begin{array}{l}-1.80 \\
(0.34)\end{array}$ & $\begin{array}{l}-1.48 \\
(0.37)\end{array}$ \\
\hline \multicolumn{6}{|l|}{ Control Variables: } \\
\hline Math Test Score at 11 & no & yes & yes & yes & yes \\
\hline Other Test Scores at 11 & no & no & yes & yes & yes \\
\hline Kerkhoff et al. type background controls & no & no & no & yes & yes \\
\hline Large set of background controls & no & no & no & no & yes \\
\hline Number of observations & 6734 & 6734 & 6734 & 6734 & 5747 \\
\hline
\end{tabular}

Note: Control variables are described in Appendix table 1

Table 2

Math Test Scores at 11

OLS Regressions

\begin{tabular}{|c|c|c|c|c|c|}
\hline Regressor & (1) & (2) & (3) & (4) & (5) \\
\hline Attends Comprehensive School & $\begin{array}{l}-8.39 \\
(0.62)\end{array}$ & $\begin{array}{l}-6.01 \\
(0.52)\end{array}$ & $\begin{array}{l}-4.91 \\
(0.46)\end{array}$ & $\begin{array}{c}-3.96 \\
(0.45)\end{array}$ & $\begin{array}{l}-3.29 \\
(0.45)\end{array}$ \\
\hline \multicolumn{6}{|l|}{ Control Variables: } \\
\hline Math Test Score at 7 & no & yes & yes & yes & yes \\
\hline Other Test Scores at 7 & no & no & yes & yes & yes \\
\hline Kerkhoff et al. type background controls & no & no & no & yes & yes \\
\hline Large set of background controls & no & no & no & no & yes \\
\hline Number of observations & 6734 & 6734 & 6734 & 6734 & 6223 \\
\hline
\end{tabular}

Note: Control variables are described in Appendix table 2 
Table 3

\section{Math Test Scores}

Dependent Variable

\begin{tabular}{|c|c|c|c|c|c|c|}
\hline \multirow{3}{*}{$\begin{array}{l}\text { Estimation Method } \\
\text { Regressor }\end{array}$} & \multicolumn{3}{|c|}{ Math Test Score at 16} & \multicolumn{3}{|c|}{ Math Test Score at 11} \\
\hline & OLS & IV & IV & OLS & IV & IV \\
\hline & (1) & (2) & (3) & (4) & (5) & $(6)$ \\
\hline $\begin{array}{l}\text { Attends Comprehensive } \\
\text { School }\end{array}$ & $\begin{array}{l}-1.88 \\
(0.35)\end{array}$ & $\begin{array}{l}-1.24 \\
(0.36)\end{array}$ & $\begin{array}{l}-1.28 \\
(0.36)\end{array}$ & $\begin{array}{l}-4.59 \\
(0.50)\end{array}$ & $\begin{array}{l}-2.90 \\
(0.62)\end{array}$ & $\begin{array}{l}-2.91 \\
(0.62)\end{array}$ \\
\hline Math Test Score at 11 & $\begin{array}{c}0.63 \\
(0.01)\end{array}$ & $\begin{array}{c}0.73 \\
(0.01)\end{array}$ & $\begin{array}{c}0.73 \\
(0.01)\end{array}$ & --- & --- & --- \\
\hline Math Test Score at 7 & --- & --- & --- & $\begin{array}{c}0.54 \\
(0.01)\end{array}$ & $\begin{array}{l}1.14 \\
(0.03)\end{array}$ & $\begin{array}{c}1.14 \\
(0.02)\end{array}$ \\
\hline Instruments: & & & & & & \\
\hline Reading Test Score at 11 & no & yes & yes & no & no & no \\
\hline Other Test Scores at 11 & no & no & yes & no & no & no \\
\hline Reading Test Score at 7 & no & no & no & no & yes & yes \\
\hline Other Test Scores at 7 & no & no & no & no & no & yes \\
\hline
\end{tabular}

Note: Endogenous regressor is the math test score at 11 . Control variables are the Kerkhoff et al. type background controls, see appendix tables. Number of observations is 6734 .

Table 4

Math Test Scores

OLS Regressions

\begin{tabular}{lcc} 
& \multicolumn{2}{c}{ Dependent Variable } \\
Math Score & $\begin{array}{c}\text { Math Score } \\
\text { at } 16\end{array}$ & $\begin{array}{c}11 \\
(1)\end{array}$ \\
Regressor & 3.49 & 5.66 \\
Attends Comprehensive School & $(0.96)$ & $(1.75)$ \\
Comprehensive School * Ability at 11 & -0.10 & --- \\
Comprehensive School * Ability at 7 & $(0.02)$ & -0.17 \\
& & $(0.03)$ \\
\hline
\end{tabular}

Note: Control variables are the Kerkhoff et al. type background controls, see appendix tables, and all test scores. Number of observations is 6734 . 
Table 5

\section{Math Test Scores}

OLS Regressions

Dependent Variable

\begin{tabular}{|c|c|c|c|c|c|c|}
\hline \multirow[b]{2}{*}{ Regressor } & \multicolumn{3}{|c|}{ Math Score at 16} & \multicolumn{3}{|c|}{ Math Score at 11} \\
\hline & (1) & $(2)$ & (3) & (4) & (5) & (6) \\
\hline Comprehensive LEA & $\begin{array}{l}-5.79 \\
(1.48)\end{array}$ & $\begin{array}{l}-1.45 \\
(1.02)\end{array}$ & $\begin{array}{c}1.63 \\
(2.64)\end{array}$ & $\begin{array}{c}-6.44 \\
(1.89)\end{array}$ & $\begin{array}{l}-4.68 \\
(1.39)\end{array}$ & $\begin{array}{c}4.60 \\
(3.16)\end{array}$ \\
\hline Comprehensive LEA * Ability at 11 & --- & --- & $\begin{array}{c}-0.06 \\
(0.05)\end{array}$ & --- & --- & --- \\
\hline Comprehensive LEA * Ability at 7 & --- & --- & --- & --- & --- & $\begin{array}{l}-0.16 \\
(0.06)\end{array}$ \\
\hline Control Variables & no & yes & yes & no & yes & yes \\
\hline
\end{tabular}

Note: Control variables are the Kerkhoff et al. type background controls, see appendix tables, and all test scores. Number of observations is 1487. Standard errors are clustered by LEA.

Table 6

Math Test Scores

IV Regressions

\begin{tabular}{|c|c|c|c|c|}
\hline \multirow[b]{3}{*}{ Regressor } & \multicolumn{4}{|c|}{ Dependent Variable } \\
\hline & \multicolumn{2}{|c|}{ Math Score at 16} & \multicolumn{2}{|c|}{ Math Score at 11} \\
\hline & (1) & $(2)$ & (3) & (4) \\
\hline Comprehensive LEA & $\begin{array}{l}-2.57 \\
(1.52)\end{array}$ & $\begin{array}{c}2.67 \\
(4.35)\end{array}$ & $\begin{array}{l}-6.16 \\
(2.13)\end{array}$ & $\begin{array}{c}4.60 \\
(3.16)\end{array}$ \\
\hline Comprehensive LEA * Ability at 11 & --- & $\begin{array}{l}-0.10 \\
(0.08)\end{array}$ & --- & --- \\
\hline Comprehensive LEA * Ability at 7 & --- & --- & --- & $\begin{array}{l}-0.12 \\
(0.09)\end{array}$ \\
\hline
\end{tabular}

Note: Endogenous regressor is comprehensive LEA. Instruments are a dummy for conservative control in 1961 for columns (1) and (3), and the dummy plus an interaction with ability at 11 in column (2), and the dummy plus an interaction with ability at 7 in column (4). Control variables are the Kerkhoff et al. type background controls, see appendix tables, and all test scores. Number of observations is 1487. Standard errors are clustered by LEA. 


\section{Appendix Table 1}

Summary Statistics for Age 16 Regressions

\begin{tabular}{|c|c|c|c|}
\hline Variable & $\begin{array}{l}\text { Number } \\
\text { of Obs. }\end{array}$ & Mean & $\begin{array}{c}\text { Standard } \\
\text { Deviation }\end{array}$ \\
\hline Math Test Score at 16 & 6734 & 42.4 & 22.4 \\
\hline Attends Comprehensive School & 6734 & 0.547 & --- \\
\hline \multicolumn{4}{|c|}{ Control Variables } \\
\hline Math Test Score at 11 & 6734 & 44.0 & 25.8 \\
\hline \multicolumn{4}{|c|}{ Other Test Scores } \\
\hline Reading Test Score at 11 & 6734 & 47.4 & 17.8 \\
\hline Verbal Test Score at 11 & 6734 & 57.7 & 23.0 \\
\hline Nonverbal Test Score at 11 & 6734 & 54.4 & 18.4 \\
\hline Design Copy Score at 11 & 6734 & 70.3 & 11.4 \\
\hline \multicolumn{4}{|c|}{ Kerkhoff et al. type background controls } \\
\hline Female & 6734 & 0.491 & --- \\
\hline Two or more siblings & 6734 & 0.608 & --- \\
\hline Twin & 6734 & 0.026 & --- \\
\hline No mother figure at 11 & 6734 & 0.005 & --- \\
\hline No father figure at 11 & 6734 & 0.034 & --- \\
\hline Father's occupation at 11: professional & 6734 & 0.055 & --- \\
\hline Father's occupation at 11: intermediate & 6734 & 0.184 & --- \\
\hline Father's occupation at 11 : skilled & 6734 & 0.519 & --- \\
\hline Father's occupation at 11: semi-skilled & 6734 & 0.161 & --- \\
\hline
\end{tabular}




\section{Appendix Table 1 (continued) Summary Statistics for Age 16 Regressions}

\begin{tabular}{|c|c|c|c|}
\hline Variable & $\begin{array}{l}\text { Number } \\
\text { of Obs. }\end{array}$ & Mean & $\begin{array}{l}\text { Standard } \\
\text { Deviation }\end{array}$ \\
\hline \multicolumn{4}{|c|}{ Large set of background controls } \\
\hline No father figure at 7 & 5747 & 0.020 & --- \\
\hline Wales & 5747 & 0.070 & --- \\
\hline Borough council & 5747 & 0.353 & --- \\
\hline Father unemployed at 11 & 5747 & 0.026 & --- \\
\hline Mother works at 11 & 5747 & 0.629 & --- \\
\hline Free meal at school at 11 & 5747 & 0.077 & --- \\
\hline Family had financial trouble last 12 months at 11 & 5747 & 0.091 & --- \\
\hline Accommodation rented from council at 11 & 5747 & 0.382 & --- \\
\hline Child doesn’t share bedroom at 11 & 5747 & 0.471 & --- \\
\hline Accommodation as bath at 11 & 5747 & 0.951 & --- \\
\hline Accommodation has indoor lavatory at 11 & 5747 & 0.899 & --- \\
\hline Has moved 2 or more times since birth at 11 & 5747 & 0.355 & --- \\
\hline Parents expect child to leave school at min. SLA & 5747 & 0.045 & --- \\
\hline Child goes to public library often at 11 & 5747 & 0.256 & --- \\
\hline Child had contact with criminal justice system betw. age 7 and 11 & 5747 & 0.015 & --- \\
\hline Missed school for 1 week to 1 month at 11 & 5747 & 0.317 & --- \\
\hline Missed school for more than 1 month at 11 & 5747 & 0.048 & --- \\
\hline Mom had health problems between age 7 and 11 & 5747 & 0.034 & --- \\
\hline Child plans to get job after school & 5747 & 0.196 & --- \\
\hline Child plans to go to university after school & 5747 & 0.290 & --- \\
\hline Watches TV most of the day at 11 & 5747 & 0.848 & --- \\
\hline Child attends private school at 11 & 5747 & 0.033 & --- \\
\hline Child attends special needs school at 11 & 5747 & 0.005 & --- \\
\hline School size at 11 & 5747 & 323.0 & 139.7 \\
\hline Class size at 11 & 5747 & 34.8 & 7.2 \\
\hline Attended two or more schools by 11 & 5747 & 0.454 & --- \\
\hline Age group tracked at 11 , higher ability track & 5747 & 0.157 & --- \\
\hline Age group tracked at 11 , intermediate ability track & 5747 & 0.111 & --- \\
\hline Age group tracked at 11 , lower ability track & 5747 & 0.091 & --- \\
\hline Teacher rating of general ability at 11 (score $1-5$ ) & 5747 & 3.06 & 0.84 \\
\hline Teacher rating of math ability at 11 (score $1-5$ ) & 5747 & 2.97 & 0.92 \\
\hline Teacher rating of use of books at 11 (score 1-5) & 5747 & 3.20 & 0.85 \\
\hline Teacher rating of oral ability at 11 (score $1-5$ ) & 5747 & 3.11 & 0.75 \\
\hline County level proportion hhs in council housing, 1971 & 5747 & 0.291 & 0.090 \\
\hline County level proportion employment manufacturing, 1971 & 5747 & 0.355 & 0.099 \\
\hline County level proportion single parents, 1971 & 5747 & 0.089 & 0.026 \\
\hline County level proportion men who are economically active, 1971 & 5747 & 0.607 & 0.018 \\
\hline County level proportion men born in UK, 1971 & 5747 & 0.940 & 0.052 \\
\hline
\end{tabular}


Appendix Table 2

Summary Statistics for Age 11 Regressions

\begin{tabular}{|c|c|c|c|}
\hline Variable & $\begin{array}{c}\text { Number } \\
\text { of Obs. }\end{array}$ & Mean & $\begin{array}{l}\text { Standard } \\
\text { Deviation }\end{array}$ \\
\hline Math Test Score at 11 & 6734 & 44.0 & 25.8 \\
\hline Attends Comprehensive School & 6734 & 0.547 & --- \\
\hline \multicolumn{4}{|c|}{ Control Variables } \\
\hline Math Test Score at 7 & 6734 & 52.9 & 24.5 \\
\hline \multicolumn{4}{|c|}{ Other Test Scores } \\
\hline Reading Test Score at 7 & 6734 & 79.4 & 22.5 \\
\hline Drawing Test Score at 7 & 6734 & 41.4 & 11.7 \\
\hline \multicolumn{4}{|c|}{ Kerkhoff et al. type background controls } \\
\hline Female & 6734 & 0.491 & --- \\
\hline Two or more siblings & 6734 & 0.608 & --- \\
\hline Twin & 6734 & 0.026 & --- \\
\hline No father figure at 7 & 6734 & 0.021 & --- \\
\hline Father's occupation at 7: professional & 6734 & 0.053 & --- \\
\hline Father's occupation at 7: intermediate & 6734 & 0.149 & --- \\
\hline Father's occupation at 7: skilled & 6734 & 0.545 & --- \\
\hline Father's occupation at 7: semi-skilled & 6734 & 0.163 & --- \\
\hline
\end{tabular}




\section{Appendix Table 2 (continued) Summary Statistics for Age 11 Regressions}

\begin{tabular}{|c|c|c|c|}
\hline Variable & $\begin{array}{l}\text { Number } \\
\text { of Obs. }\end{array}$ & Mean & $\begin{array}{l}\text { Standard } \\
\text { Deviation }\end{array}$ \\
\hline \multicolumn{4}{|c|}{ Large set of background controls } \\
\hline Wales & 6223 & 0.071 & --- \\
\hline Borough council & 6223 & 0.345 & --- \\
\hline Mother worked before child started school & 6223 & 0.443 & --- \\
\hline Accommodation rented from council at 7 & 6223 & 0.376 & --- \\
\hline Accommodation as bath at 7 & 6223 & 0.891 & --- \\
\hline Accommodation has indoor lavatory at 7 & 6223 & 0.840 & --- \\
\hline Parents read to child hardly ever at 7 & 6223 & 0.108 & --- \\
\hline Child talked at age 2 & 6223 & 0.943 & --- \\
\hline Age child started school & 6223 & 4.66 & --- \\
\hline Attends private school at 7 & 6223 & 0.029 & --- \\
\hline Child attends special needs school at 7 & 6223 & 0.002 & --- \\
\hline School size at 7 & 6223 & 246.7 & 121.5 \\
\hline Class size at 7 & 6223 & 35.4 & 7.2 \\
\hline $30 \%$ or more of dads in child's class in non-manual occupation & 6223 & 0.238 & --- \\
\hline Occupation of dads in child's class missing & 6223 & 0.230 & --- \\
\hline Age started reading in school & 6223 & 5.47 & 0.67 \\
\hline Age started math in school & 6223 & 5.57 & 0.63 \\
\hline $\begin{array}{l}\text { Gets help in school for mental backwardness, disability, or } \\
\text { behavior problem }\end{array}$ & 6223 & 0.047 & --- \\
\hline Gets no help in school but needs help for problem & 6223 & 0.095 & --- \\
\hline Child settled at school within one month & 6223 & 0.719 & --- \\
\hline Age group tracked at 7 , higher ability track & 6223 & 0.041 & --- \\
\hline Age group tracked at 7 , intermediate ability track & 6223 & 0.017 & --- \\
\hline Age group tracked at 7 , lower ability track & 6223 & 0.020 & --- \\
\hline Teacher rating of oral expression at 7 (score $1-5$ ) & 6223 & 3.18 & 0.94 \\
\hline Teacher rating of awareness of world at 7 (score 1-5) & 6223 & 3.00 & 0.83 \\
\hline Teacher rating of reading ability at 7 (score $1-5$ ) & 6223 & 3.16 & 0.90 \\
\hline Teacher rating of creativity at 7 (score $1-5$ ) & 6223 & 2.93 & 0.82 \\
\hline Teacher rating of reading ability at 7 (score $1-5$ ) & 6223 & 2.91 & 0.85 \\
\hline County level proportion hhs in council housing, 1971 & 6223 & 0.291 & 0.090 \\
\hline County level proportion employment manufacturing, 1971 & 6223 & 0.355 & 0.099 \\
\hline County level proportion single parents, 1971 & 6223 & 0.089 & 0.026 \\
\hline County level proportion men who are economically active, 1971 & 6223 & 0.607 & 0.018 \\
\hline County level proportion men born in UK, 1971 & 6223 & 0.940 & 0.052 \\
\hline
\end{tabular}


Appendix Table 3

Treatment and Control LEAs

\begin{tabular}{ll} 
Selective LEAs & Comprehensive LEAs \\
\hline Barrow in Furness & Anglesey \\
Blackpool & Blackburn \\
Bolton & Cardiff \\
Bournemouth & Carlisle \\
Brighton & Darlington \\
Buckinghamshire & Flintshire \\
Burton upon Trent & Gateshead \\
Canterbury & Isle of Wight \\
Cheshire & Leicestershire \\
Dewsbury & Luton \\
Dudley & Merioneth \\
Eastbourne & Montgomeryshire \\
Great Yarmouth & Newcastle upon Tyne \\
Halifax & Newport \\
Hastings & Norwich \\
Ipswich & Oldham \\
Leicester & Oxfordshire \\
Norfolk & Preston \\
Portsmouth & Rochdale \\
Solihull & Rotherham \\
South Shields & Sheffield \\
Southend on Sea & Stoke on Trent \\
Southport & Swansea \\
Torbay & Tynemouth \\
Warley & Wallasey \\
Warrington & West Bromwich \\
Warwickshire & \\
Worcester & \\
York & \\
\hline
\end{tabular}

